\title{
Assessing the Accuracy of Low-cost Surgical Guides Generated Using Ridge Mapping by Means of Cone Beam Computerized Tomography
}

\author{
Khyati Gupta ${ }^{1}$, Sameep Singh ${ }^{2}$, Satyavir Singh ${ }^{3}$
}

\begin{abstract}
Aim: Assessing the accuracy of surgical guides generated with the help of a simple chair side ridge mapping technique by comparing the planned implant position with the achieved implant position on post-op computerized tomography scans.

Materials and methods: In this study, 20 implant sites in patients were selected. Ridge mapping was done through a vacuum press template at three buccal (B1, B2, B3), three lingual $(L 1, L 2, L 3)$, and one crestal (C) points for each implant site. Readings were transferred onto the cast, and surgical guides were fabricated for implant placement. Postoperative cone beam computerized tomography (CBCT) was done to assess planned and achieved implant position. Comparison was done between soft tissue depths and implant distance from the crest of alveolar bone determined by the ridge mapping technique with measurements done on CBCT. The points used for ridge mapping were used as the reference for measurements. The data were analyzed using paired $t$ test. $p<0.05$ was considered to be statistically significant.

Results: On comparing the mean values of soft tissue depths from the ridge mapping and CBCT data, insignificant differences were found at $B 1$, $B 2, L 1, L 2, L 3$, and C, but significant differences were found at B3. On comparing the implant distances from alveolar bone from both the data, insignificant differences were found at B, B2, B3, L1, L2, and L3 and significant difference was found at the crest in the mean values.

Conclusion: Under the limitations of the above study, it can be concluded that a simple chairside procedure like ridge mapping can be used as an effective way for guided implant placement in sufficient available alveolar bone.
\end{abstract}

Keywords: Cone beam computerized tomography, Flapless surgery, Guided surgery, Ridge mapping, Surgical guide.

The Journal of Contemporary Dental Practice (2019): 10.5005/jp-journals-10024-2627

\section{INTRODUCTION}

The foremost challenge in flapless implant placement is the correct spatial positioning of the dental implant in the bone. ${ }^{1}$ Determination of proper angulation of implant placement according to the future prosthesis should be done with the consideration of buccolingual, apicocoronal, and mesiodistal positions. ${ }^{2}$ Bone evaluation limited to the use of panoramic and/or periapical radiographs may be insufficient because it only provides two-dimensional information about implant sites. ${ }^{3}$ The third dimension, i.e., the buccolingual width, can be assessed with the help of methods like ridge mapping and also with modern diagnostic aids, such as computerized tomography (CT).

$\mathrm{CT}$ is a helpful tool in the rehabilitation of complex implant cases with anatomic limitations. But for most dental practitioners, the use of advanced imaging has been limited because of the cost, availability, and/or radiation dose considerations.

One way to achieve advantages of a flapless procedure but at the same time avoid the disadvantages of computerized tomography is ridge mapping. It provides instant information which can be used in the fabrication of surgical guides at reduced costs. Colombo et al. critically reviewed studies based on randomized clinical trials for clinical applications and effectiveness of guided surgery and found insignificant differences between conventional and guided placement of implants for clinical outcome and implant survival. ${ }^{4}$

Hence, the purpose of this study was to assess the difference between the planned position of implants placed through low-cost surgical guides fabricated by the ridge mapping technique and the achieved position of implants measured on a postoperative CBCT of the implant site.
${ }^{1}$ Department of Prosthodontics, AIMST University, Semeling, Bedong, Kedah, Malaysia

${ }^{2}$ Department of Pediatric and Preventive Dentistry, Medeor Hospitals, New Delhi, India

${ }^{3}$ Department of Prosthodontics, Santosh Dental College, Ghaziabad, Uttar Pradesh, India

Corresponding Author: Khyati Gupta, AIMST University, Semeling, Bedong, Kedah, Malaysia, Phone: +60 1136159753, e-mail: Khyati.doc. gupta@gmail.com

How to cite this article: Gupta K, Singh S, et al. Assessing the Accuracy of Low-cost Surgical Guides Generated Using Ridge Mapping by Means of Cone Beam Computerized Tomography. J Contemp Dent Pract 2019;20(8):907-914.

Source of support: Nil

Conflict of interest: None

\section{Materials and Methods}

In this study, after ethical clearance from the ethics committee of Sri Govind Tricentenary Dental College, Hospital and Research Institute, Gurugram, India, 20 implant sites in patients with partially or fully edentulous maxilla or mandible were selected. The patients had enough alveolar bone and good oral hygiene. The exclusion criteria were systemic or psychological conditions, parafunctional habits, and/or chronic periodontitis. Diagnostic orthopantomograms (Fig. 1) and periapical radiographs were taken for all patients. Written consent was obtained from all subjects, and they were fully explained the purpose of the study and the steps involved.

o The Author(s). 2019 Open Access This article is distributed under the terms of the Creative Commons Attribution 4.0 International License (https://creativecommons. org/licenses/by-nc/4.0/), which permits unrestricted use, distribution, and non-commercial reproduction in any medium, provided you give appropriate credit to the original author(s) and the source, provide a link to the Creative Commons license, and indicate if changes were made. The Creative Commons Public Domain Dedication waiver (http://creativecommons.org/publicdomain/zero/1.0/) applies to the data made available in this article, unless otherwise stated. 


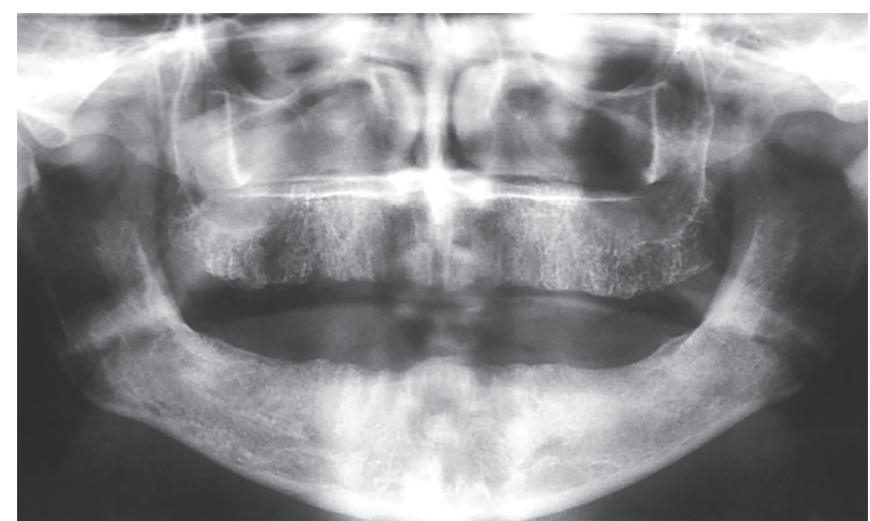

Fig. 1: Preoperative OPG

\section{Ridge Mapping Technique}

Irreversible hydrocolloid impressions (Zelgan 2002, Dentsply) were made of the patient's arches, and diagnostic casts were poured in Type III gypsum (Zhermack Elite Rock Diestone). A vacuum-press template (Fig. 2) was fabricated using a $1 \mathrm{~mm}$ biocryl sheet on the stone cast. Three pairs of equidistant ( $2 \mathrm{~mm}$ ) buccal/lingual points and one point on the crest were defined at each implant site on the cast and transferred to the template. Local anesthetic solution (XICAINE, aignocaine hydrochloride I.P., 2\% adrenaline I.P. 1:80,000) was administered to each mapping site by infiltration. The mapping template was placed in the patient's mouth, and soft tissue was marked using a William's probe \#4 (API GERMANY STAINLESS STEEL) with an endodontic rubber stopper (Fig. 3). The same probe was then used to measure the thickness of the mucosa after removing the mapping guide and readings were recorded.

\section{Surgical Guide Fabrication}

The cast was sectioned along the lines made by joining the reference points at each implant site, and the underlying ridge topography was drawn on the die cross sections (Fig. 4) by transferring the mucosal thickness at each reference point. The casts were mounted with accurate jaw relation record for each patient, and prosthetic positioning of implants was planned based on old patient dentures, diagnostic wax-ups, etc. The cast was drilled along each implant site according to the determined buccolingual angulation (Fig. 5).

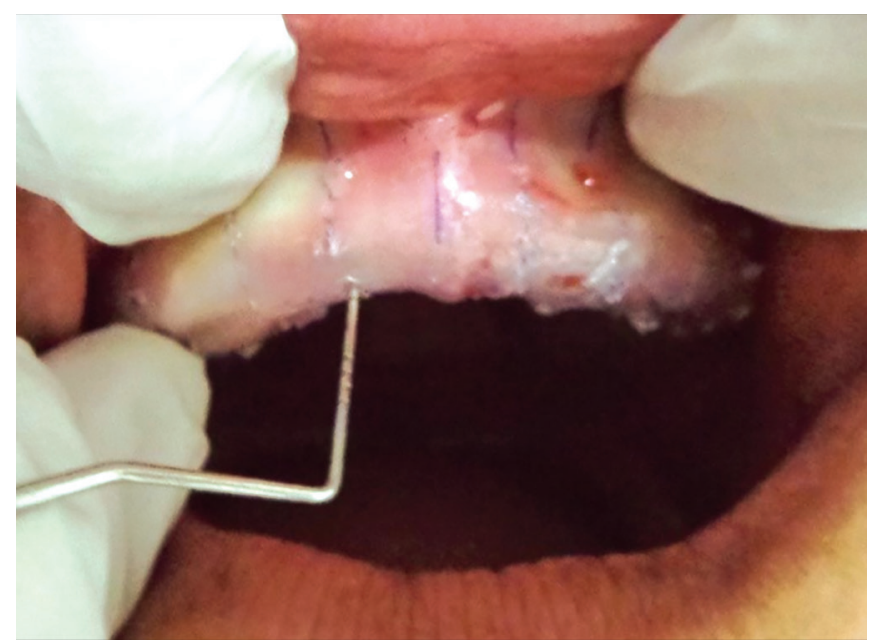

Fig. 3: Ridge mapping

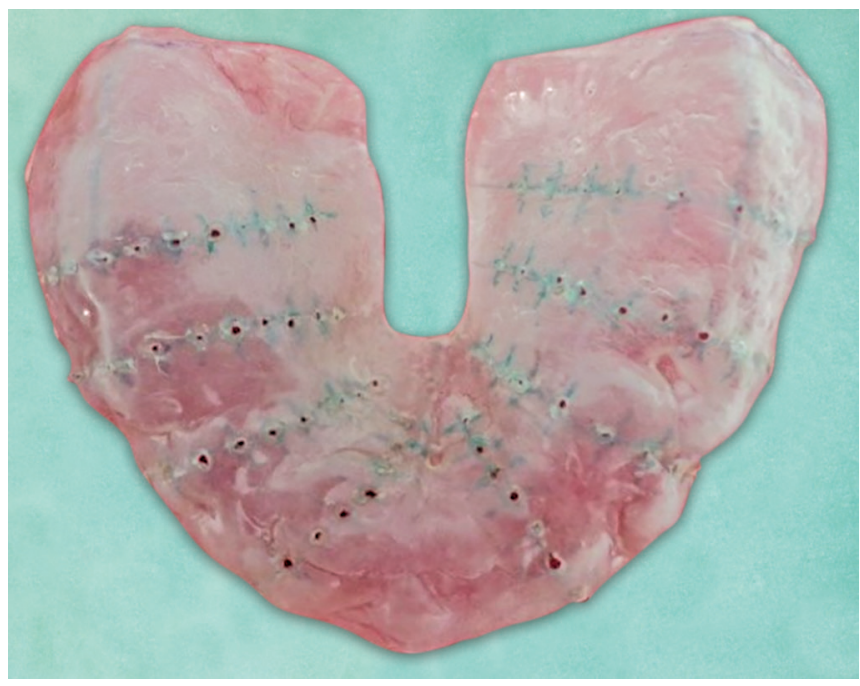

Fig. 2: Vacuum press template

The surgical guide was fabricated on the cast using clear acrylic, and metallic carrier sleeves were incorporated at each site at the planned angulation (Figs 6 and 7).

The implant size was selected according to the bone mapping and radiographic evaluation. The surgical guide was placed in the patient's mouth and stabilized using titanium screws if required (Fig. 8). The soft tissue at each site was punched using a tissue punch of $5 \mathrm{~mm}$ diameter through metallic carrier sleeves in the surgical guide (Fig. 9). Osteotomies were done through the surgical guide using a universal guided surgery kit (Fig. 10). The implants were placed in the bone through the surgical guide.

Postoperative CT scan (Dentascan) was done for the patient's implant sites after placement of the implant for assessing the accuracy of ridge mapping measurements.

\section{Recording of Data for Analysis}

For the soft tissue depth analysis on CT scan, a radiographic template (a complete denture or acrylic plate) with barium sulfate coating on the tissue surface was placed over the implant sites after implant placement during the CT scan procedure. The points used for ridge mapping were used as the reference for measurements, three points each on the buccal surface (B1, B2, B3), three on the

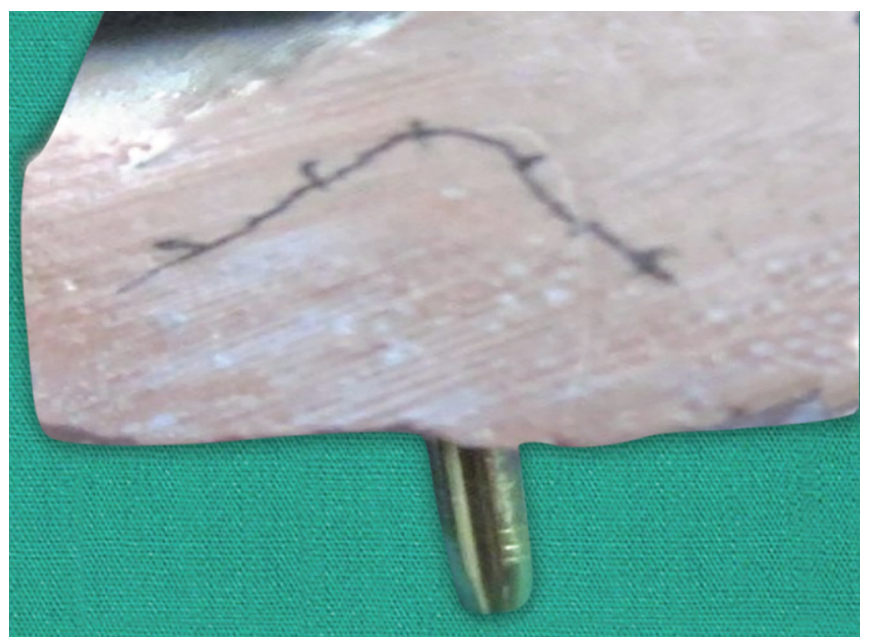

Fig. 4: Die cross section 


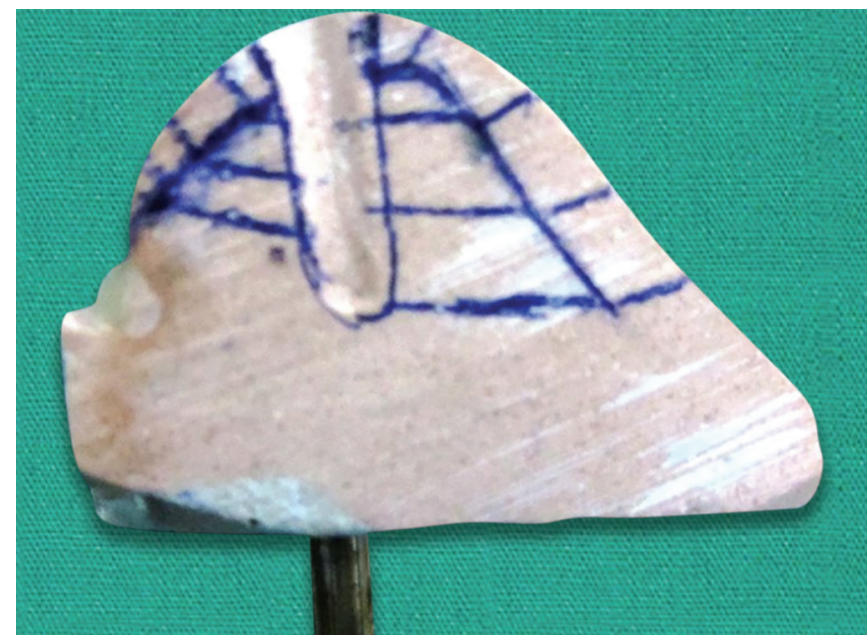

Fig. 5: Planning implant position

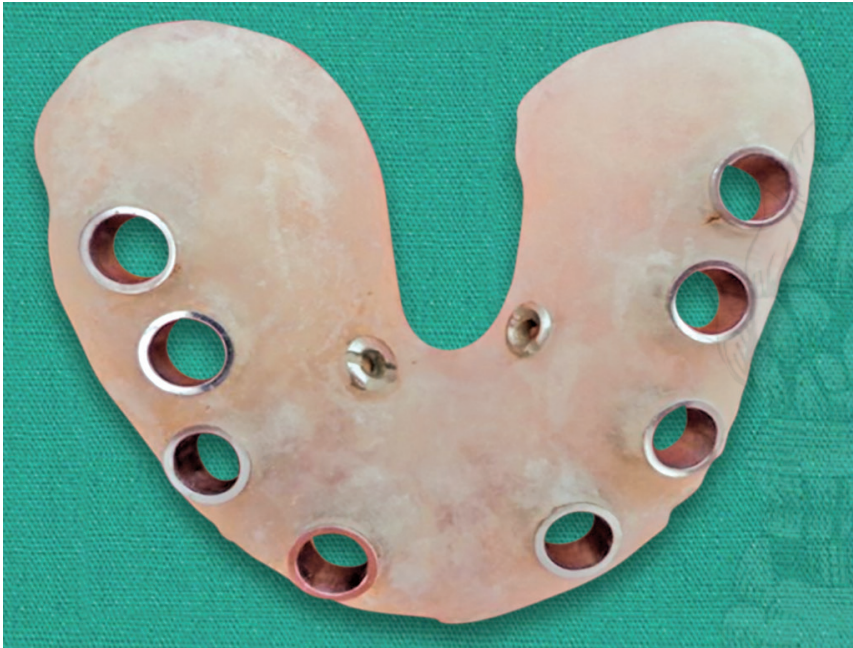

Fig. 7: Surgical guide

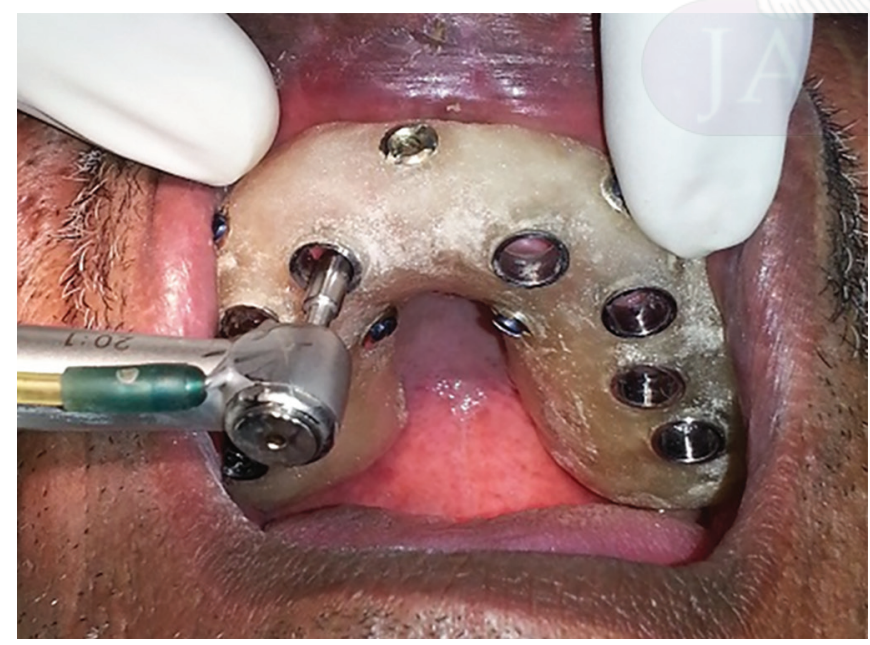

Fig. 9: Tissue punch

lingual surface $(L 1, L 2, L 3)$ and one the crest $(C)$. The distance of the ridge crest to the alveolar bone was measured at each point on the CT scan. This was then compared to the ridge mapping readings analyzed.

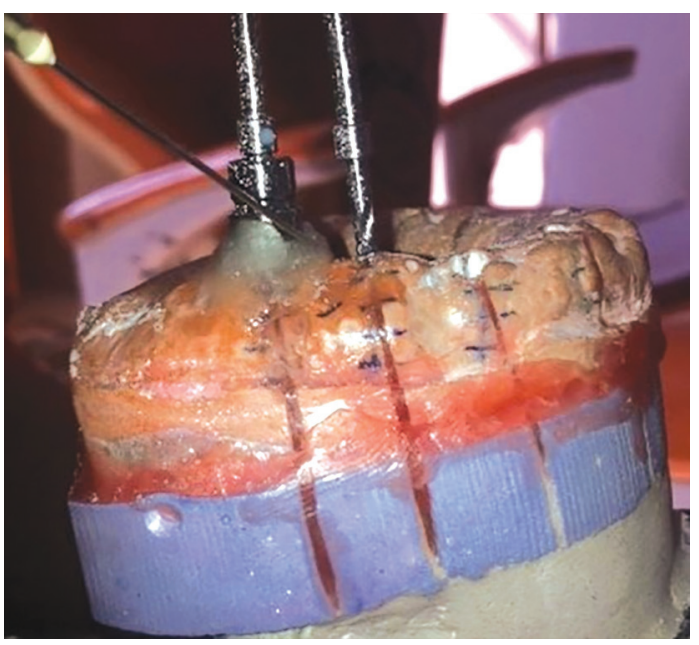

Fig. 6: Fabrication of surgical guide

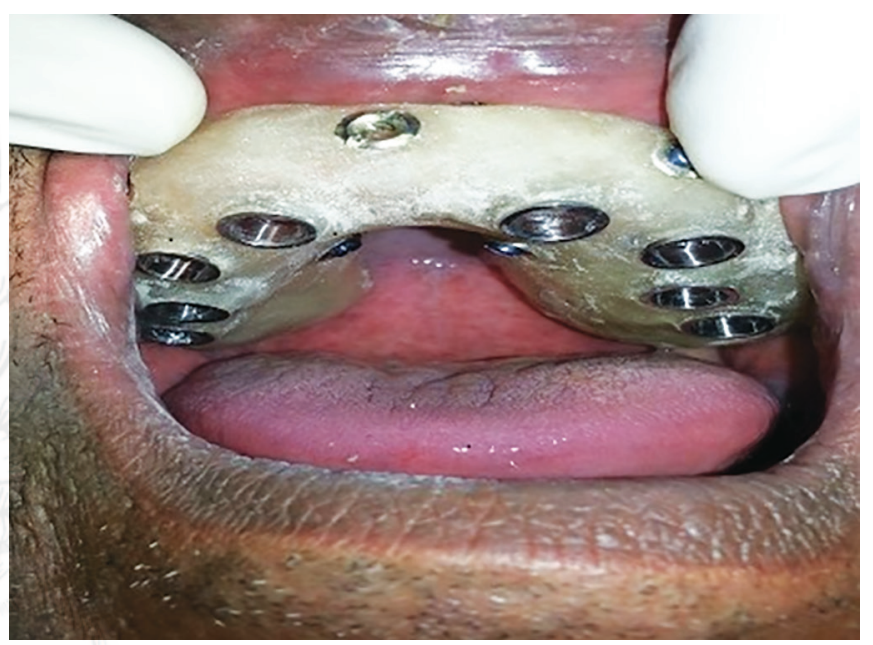

Fig. 8: Stabilizing the guide

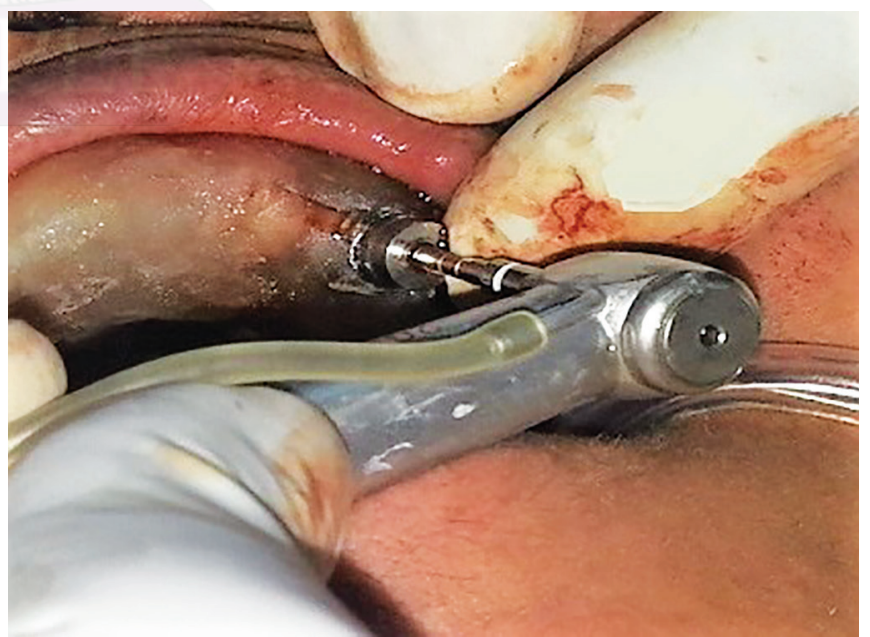

Fig. 10: Drilling the implant site

For the implant position analysis, the distance from the alveolar bone to the implant was measured with the same points as reference on the cast and on the CT scan. On the cast, the measurement was done till the periphery of the drill marks which were made with the 


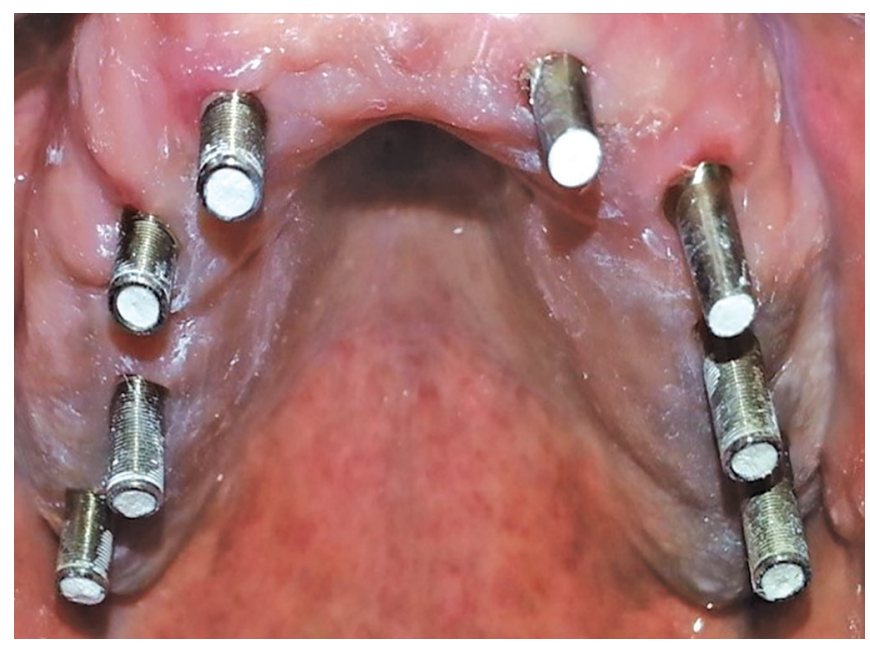

Fig. 11: Abutments placed

final drill during template fabrication. The data for the two were compared and analyzed. The readings were statistically analyzed using paired $t$ test.

\section{Loading of the Implants and Prosthodontic Procedures}

Immediate or delayed loading of the implants was done. A metal ceramic prosthesis was fabricated. The crowns were cemented on the abutment after establishing proper occlusion (Figs 11 and 12).

\section{Results}

The mean of distances at all points was calculated for all the 20 implants for both soft tissue depth and implant position and compared. The data for ridge mapping and CT were compared (Tables 1 and 2) (Figs 13 to 15).

Table 1 and Figures 13 to 15 show that for the soft tissue depth, the mean values at the three buccal points-B1, B2, and B3-in the ridge mapping data ( $\mathrm{RMB1}, \mathrm{RMB2}$, and $\mathrm{RMB3})$ were $2.275 \pm 0.734$, $2.325 \pm 0.893$, and $2.975 \pm 1.186$, respectively. The mean values in the CT data (CTB1, CTB2, and CTB3) were $2.235 \pm 0.766,2.310 \pm$ 0.882 and $2.900 \pm 1.130$, respectively. On comparing the two data,

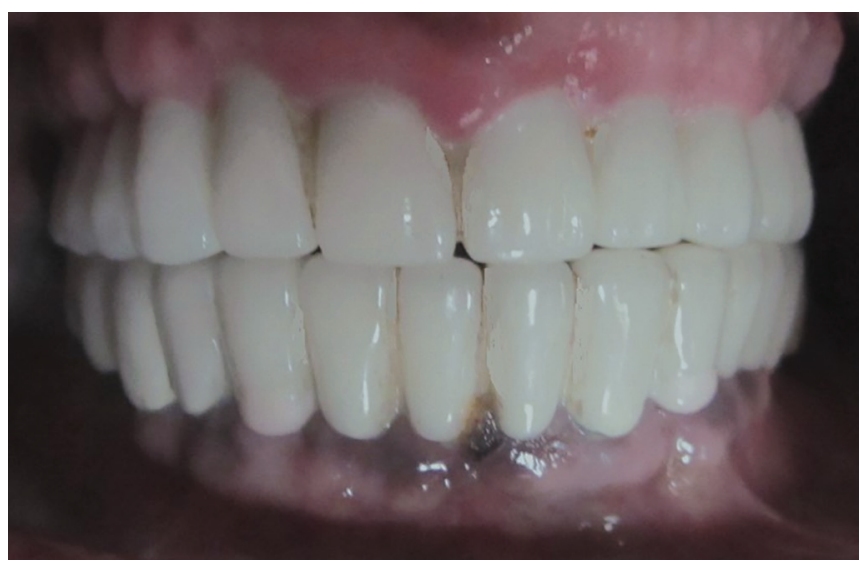

Fig. 12: Permanent restoration cemented

insignificant differences were found at B1 and B2 ( $p$ value 0.148 and 0.186), but significant differences were found at B3 ( $p$ value 0.036). For the soft tissue depth, the mean values at the three lingual points - L1, L2, and L3 - in the ridge mapping data (RML1, RML2, and RML3) were $3.075 \pm 0.878,3.225 \pm 1.446$, and $3.075 \pm$ 1.370, respectively. The mean values in the CT data (CTL1, CTL2, and CTL3) were $3.035 \pm 0.905,3.070 \pm 1.217$, and $2.890 \pm 1.059$, respectively. On comparing the two data, insignificant differences were found at all the three points - L1, L2 and L3 ( $p$ value $0.104,0.142$ and 0.231 , respectively). The mean values at the crest in the ridge mapping data (RMC) were $3.200 \pm 0.849$ and for the $\mathrm{CT}$ data were $3.165 \pm 0.910$. On comparing the two data, insignificant differences were found in the crest values ( $p$ value 0.273 ).

Table 2 and Figs 13 to 15 show that for the implant position, the mean values at the three buccal points-B1, B2, and B3-in the ridge mapping data (RMB1, RMB2, and RMB3) were $1.500 \pm 0.669$, $2.306 \pm 0.987$, and $2.708 \pm 1.456$, respectively. The mean values in the CT data (CTB1, CTB2, and CTB3) were $1.530 \pm 0.812,2.183 \pm 1.053$, and $2.623 \pm 1.482$, respectively. On comparing the two data, insignificant differences were found at all the three points B1, B2, and B3 ( $p$ value $0.753,0.221$, and 0.51 , respectively). For the implant position, the mean values at the three lingual points - $\mathrm{L} 1, \mathrm{~L} 2$, and $\mathrm{L} 3$ - in the ridge mapping data (RML1, RML2, and RML3) were $1.510 \pm 0.763,2.025 \pm$ 0.993 , and $2.806 \pm 1.354$, respectively. The mean values in the CT

Table 1: Represents comparison of soft tissue depths at selected points at all implant sites by ridge mapping and on the CT scan

\begin{tabular}{|c|c|c|c|c|c|c|}
\hline \multicolumn{7}{|c|}{ Paired samples statistics } \\
\hline & & $N$ & Mean & Std. deviation & tvalue & $p$ value \\
\hline \multirow[t]{2}{*}{ Pair 1} & RMB1 & 20 & 1.500 & 0.669 & 0.32 & 0.753 \\
\hline & CTB1 & 20 & 1.530 & 0.812 & & \\
\hline \multirow[t]{2}{*}{ Pair 2} & RMB2 & 18 & 2.306 & 0.987 & 1.271 & 0.221 \\
\hline & СТВ2 & 18 & 2.183 & 1.053 & & \\
\hline \multirow[t]{2}{*}{ Pair 3} & RMB3 & 13 & 2.708 & 1.456 & 0.68 & 0.51 \\
\hline & СТВ3 & 13 & 2.623 & 1.482 & & \\
\hline \multirow[t]{2}{*}{ Pair 4} & $\mathrm{RMC}$ & 20 & 0.000 & 0.000 & 2.219 & $0.047^{*}$ \\
\hline & CTC & 20 & 0.085 & 0.179 & & \\
\hline \multirow[t]{2}{*}{ Pair 5} & RML1 & 20 & 1.510 & 0.763 & 0.302 & 0.766 \\
\hline & CTL1 & 20 & 1.490 & 0.789 & & \\
\hline \multirow[t]{2}{*}{ Pair 6} & RML2 & 20 & 2.025 & 0.993 & 1.152 & 0.264 \\
\hline & CTL2 & 20 & 2.155 & 1.022 & & \\
\hline \multirow[t]{2}{*}{ Pair 7} & RML3 & 16 & 2.806 & 1.354 & 0.789 & 0.442 \\
\hline & CTL3 & 16 & 2.888 & 1.379 & & \\
\hline
\end{tabular}






Fig. 13: Graph represents mean of soft tissue depths and implant distance on the buccal aspect of the ridge at all implant sites by ridge mapping as well as on the CT scan

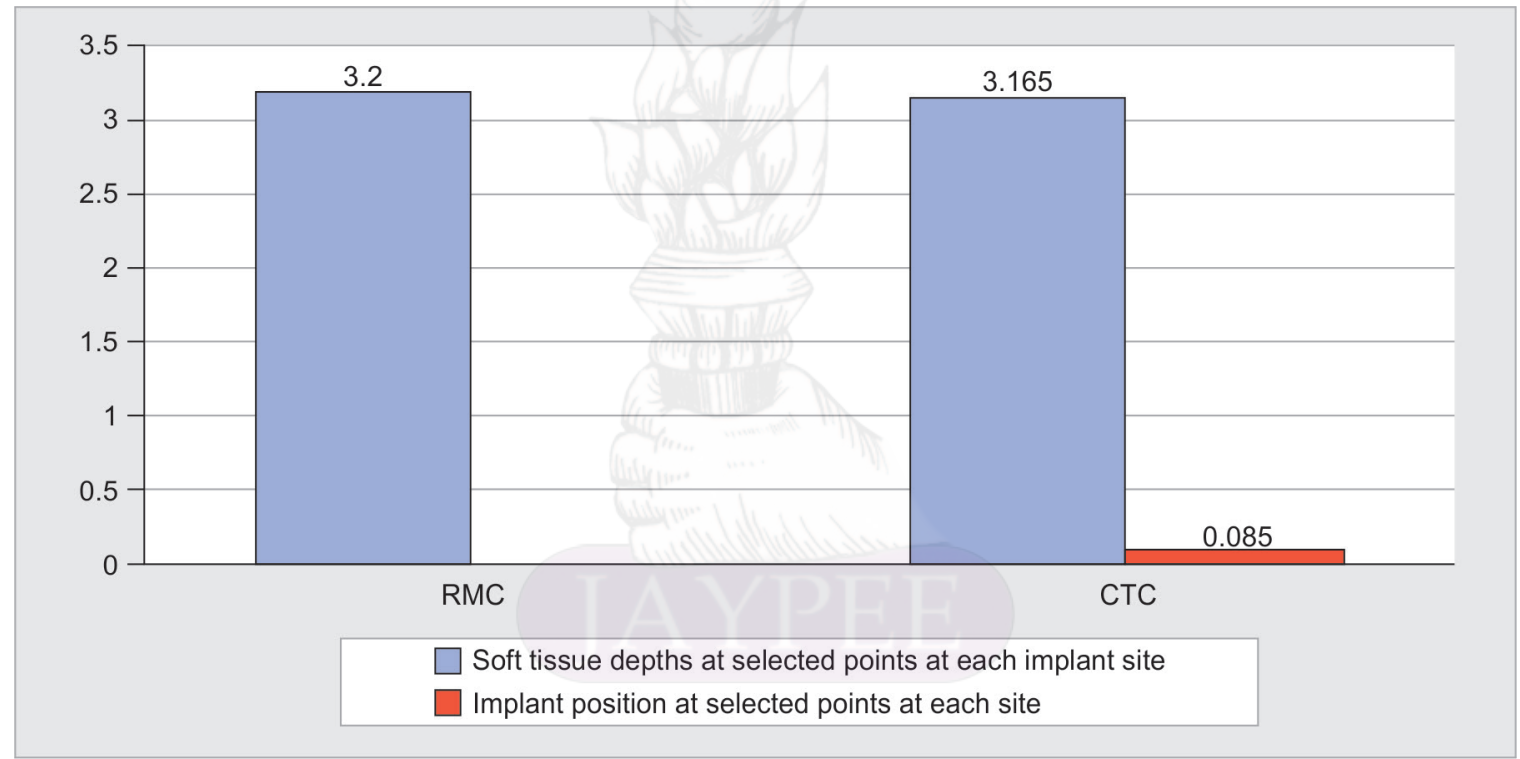

Fig. 14: Graph represents mean of soft tissue depths and implant distance on the crest of the ridge at all implant sites by ridge mapping as well as on the CT scan

data (CTL1, CTL2, and CTL3) were $1.490 \pm 0.789,2.155 \pm 1.022$, and $2.888 \pm 1.379$, respectively. On comparing the two data, insignificant differences were found at all the three points-L1, L2 and L3 ( $p$ value $0.766,0.264$, and 0.442 , respectively). The mean values at the crest in the ridge mapping data (RMC) were $0.000 \pm 0.000$ and for the CT data were $0.085 \pm 0.179$. On comparing the two data, significant differences were found in the crest values ( $p$ value 0.047).

\section{Discussion}

Hiroshima and Nagasaki atomic bomb survivors received exposures of 10-100 millisieverts (mSv) and have been identified with an increased risk of cancer. ${ }^{5}$ Equivalent exposures can be delivered by a single $\mathrm{CT}$ scan and increased risk may occur for patients who might undergo multiple exposures. ${ }^{6,7}$ Thus, in this study we have advocated the use of conventional ridge mapping-generated surgical guides over CT-generated surgical guides for flapless implant placement.

Although the inherent ability of CT to separate different soft tissue densities facilitates visualization of the mandibular canal, the true thickness of the cortical bone may not be reliably depicted because of the volume averaging and computer algorithm limitations of CT procedures. ${ }^{8}$ Also, it may be difficult to accurately correlate the radiographic location with the clinical landmarks, such as teeth. Slight alterations in the width of the alveolus may not appear significant on the scan but could well mean a smaller diameter root form implant. The clarity of CT images is disturbed by artifacts, noise, and poor soft tissue contrast. ${ }^{9}$ A large number of 


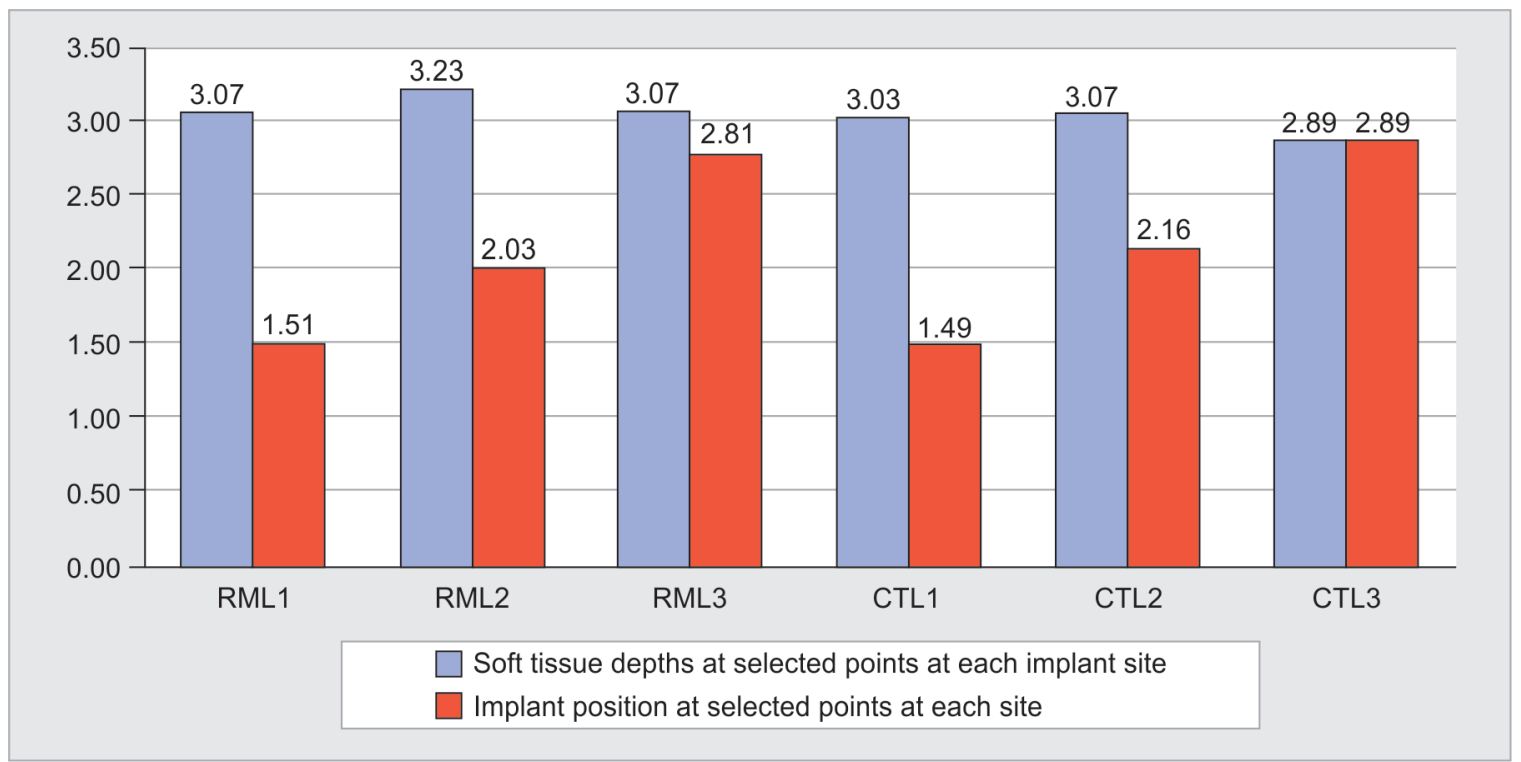

Fig. 15: Graph represents mean of soft tissue depths and implant distance on the lingual aspect of the ridge at all implant sites by ridge mapping as well as on the CT scan

Table 2: Represents the implant position at selected points at all implant sites on the ridge mapped cast and on the CT scan

\begin{tabular}{|c|c|c|c|c|c|c|}
\hline \multicolumn{7}{|c|}{ Paired samples statistics } \\
\hline & & $N$ & Mean & Std. deviation & tvalue & $p$ value \\
\hline \multirow[t]{2}{*}{ Pair 1} & RMB1 & 20 & 2.275 & 0.734 & 1.506 & 0.148 \\
\hline & СТВ1 & 20 & 2.235 & 0.766 & & \\
\hline \multirow[t]{2}{*}{ Pair 2} & RMB2 & 20 & 2.325 & 0.893 & 1.371 & 0.186 \\
\hline & СТВ2 & 20 & 2.310 & 0.882 & & \\
\hline \multirow[t]{2}{*}{ Pair 3} & RMB3 & 20 & 2.975 & 1.186 & 2.263 & $0.036^{*}$ \\
\hline & СТВ3 & 20 & 2.900 & 1.130 & & \\
\hline \multirow[t]{2}{*}{ Pair 4} & $\mathrm{RMC}$ & 20 & 3.200 & 0.849 & 1.129 & 0.273 \\
\hline & CTC & 20 & 3.165 & 0.910 & & \\
\hline \multirow[t]{2}{*}{ Pair 5} & RML1 & 20 & 3.075 & 0.878 & 1.71 & 0.104 \\
\hline & CTL1 & 20 & 3.035 & 0.905 & & \\
\hline \multirow[t]{2}{*}{ Pair 6} & RML2 & 20 & 3.225 & 1.446 & 1.532 & 0.142 \\
\hline & CTL2 & 20 & 3.070 & 1.217 & & \\
\hline \multirow[t]{2}{*}{ Pair 7} & RML3 & 20 & 3.075 & 1.370 & 1.237 & 0.231 \\
\hline & CTL3 & 20 & 2.890 & 1.059 & & \\
\hline
\end{tabular}

inaccuracies exist in data acquisition for computer-guided surgeries owing to cumulative and interactive errors in the process; hence, computer-guided surgery cannot be considered to be better than conventional surgery due to lack of any definite evidence. ${ }^{10}$ Van Assche et al. placed 12 implants in 4 formalin-fixed cadaver jaws. Upon comparison with the planned implants, we noted average angular deviation of $2 \pm 0.8$ degrees and mean linear deviation of $1.1 \pm 0.7 \mathrm{~mm}$ at the neck and $2 \pm 0.7 \mathrm{~mm}$ at the apex in the placed implants. ${ }^{11}$

Bone calipers have been advocated for ridge mapping. Perez et al. compared the accuracy of linear tomography (LT) and direct ridge mapping $(\mathrm{RM})$ for determining alveolar ridge dimensions using an imaging stent containing 2-mm metal balls for linear tomographic measurements, while the RM stent had holes drilled at coronal, middle, and apical intersection and found that there were no significant differences between LT and RM for ridge width measurements. ${ }^{12}$ However, both techniques underestimated ridge dimensions compared to direct measurements $(p<0.05)$. However, a caliper can measure only the ridge width and not its shape. So to determine the correct buccolingual angulation of the implant, one needs to know the ridge topography and this will result in increased accuracy in implant placement. Hence, in this study ridge mapping was done which facilitated the measurement of soft tissue depths at multiple points for every implant site and the alveolar ridge topography was reproduced. Thus, the buccolingual angulation of the implant could be planned.

Stumpell LJ used an injection needle with a rubber stopper to measure soft tissue thickness at five points one on the crest, one each on the most apical part of the proposed implant site on the buccal and lingual side and one each midway between these two points to determine the buccolingual ridge dimensions. ${ }^{1}$ This was then arbitrarily transferred to the cast. But in this study, we 
used a vacuum-formed template of minimal thickness so that the measurements could be accurately transferred to the cast. We used seven points at $3 \mathrm{~mm}$ distance for ridge mapping at each site since increasing the number decreases the chances of error especially if the clinical situation appears more irregular. Also, in this study a William's probe with a rubber stopper was used since injection needles, endodontic files, endodontic explorer with a rubber stopper, or an endodontic spreader with a rubber stopper could easily penetrate softer ridges and give erroneous readings.

It has been shown that unanticipated bone grafting procedures might be needed when only ridge mapping has been used for preoperative assessment in the anterior maxilla. On the other hand, a recent study found that ridge mapping measurements were more consistent than measurements made by $\mathrm{CBCT} .^{13}$ Another disadvantage with ridge mapping is multiple pricks given to the patient both for infiltration of the local anesthetic and during ridge mapping. This can cause discomfort to the patient and sometimes may even lead to infection; in our study, we kept the patient under an antibiotic cover before ridge mapping to prevent any chances of infection.

In this study, we used conventionally fabricated surgical guides using acrylic resin which have a greater accuracy of fit than CBCT scanned surgical guides. ${ }^{14}$

Burns et al. set metal tubes in the guide using a surveyor at the proposed center of restoration with the desired angulation and used acrylic resin to fix the tubes in place. ${ }^{15}$ In this study, the material of choice was self-cure acrylic resin with metallic carrier sleeves incorporated into them. A complete-limiting design of the surgical guide was used to prevent any intraoperative variations and accurate transfer of the planned implant positions. ${ }^{16}$

According to a study by Park et al., precision surgical guides with a 4-mm occluso-gingival height allow placement as accurate at $8 \mathrm{~mm}$ height, for both freehand and guided implant placement. ${ }^{17}$ During the surgery, problems were encountered with access in the posterior region with surgical guide assembly in place which further reduced the available interocclusal distance. Hence, shorter length reducers should be preferred in the posterior region and the planned implant length should be as minimum as possible with guided implants in the posterior region.

An important consideration in using surgical guides is their fixation in the mouth during implant placement. A variety of surgical guides have been described in the literature, ${ }^{18}$ but a major disadvantage of most surgical guides is the lack of stability in the edentulous patient, especially when the guides are supported only by the remaining soft tissues and relieved from the lingual or palatal aspect for surgical access. ${ }^{19}$ If the template is not fixed horizontally to the bone there is a risk in improper seating of the template, which will result in mal-alignment of the implants. In this study, surgical fixation screws of $1.5 \mathrm{~mm}$ diameter and $6 \mathrm{~mm}$ length, used in oral surgery for fixation of bone fragments, were used. The size and location of the screws were such that it did not interfere with the implant position or cause any injury to the adjacent vital structures.

Copious irrigation was done at each site during the osteotomy preparation to remove any debris and keep the site cool, which was necessary due to the closed environment created by the surgical guide.

As anticipated with a flapless approach, minimum patient discomfort was observed postsurgically. A postoperative CT scan was done to assess the achieved implant position in this study since a high-resolution CT scan is capable of producing images comparable to histological sections. ${ }^{20}$ The implant could be immediately loaded and excellent healing was seen on follow-up.

The results of the study showed insignificant differences between soft tissue depth and implant position on comparing ridge mapping and $C B C T$ data. For soft tissue depth, significant differences were found only at one point B3. This can be attributed to the fact as we go nearer to the vestibule; due to the presence of loose and highly compressible soft tissue, the ridge mapping readings could be aberrant. To avoid this, we suggest decreasing the distance between points from $3 \mathrm{~mm}$ to $2 \mathrm{~mm}$. For implant position, significant differences were found at the crestal levels. This highly depends on individual operator skills as the implants were screwed in after removal of the surgical guide from the site. To prevent this, implant placement should also be carried out with surgical guides in place.

Limitations of the study include case selection limited to implant sites with alveolar ridges of good height and width. Furthermore, standardization of the technique for surgical guide fabrication is required to minimize errors in fabrication. Patients may not be comfortable with the ridge mapping procedure due to multiple pricking and administration of local anesthesia.

\section{Conclusion}

Under the limitations of the above study, it can be concluded that simple chairside procedures like ridge mapping can be used as an effective way for guided implant placement in sufficient available alveolar bone, thus reducing the costs and complications of the much-advanced computerized tomography-guided implant placement.

\section{Clinical Significance}

Reduction in the cost of surgical guides used for guided implant placement should be considered.

\section{References}

1. Stumpel LJ III. Cast-based guided implant placement: a novel technique. J Prosthet Dent 2008;100:61-69. DOI: 10.1016/S00223913(08)60140-7.

2. Nikolidakis D, Sykaras N. Removal of a malpositioned implant and immediate reimplantation during healing period. Dent Oral Craniofac Res 2017;4(3):1-4. DOI: 10.15761/DOCR.1000248.

3. Dave BH, Sutaria $\mathrm{S}$, et al. A comparative study of three different methods for evaluating width of alveolar ridge prior to implant placement: An in vivo study. Int J Oral Care Res 2017;5(1):1-8. DOI: 10.5005/jp-journals-10051-0082.

4. Colombo M, Mangano C, et al. Clinical applications and effectiveness of guided implant surgery: a critical review based on randomized controlled trials. BMC Oral Health 2017;17:150. DOI: 10.1186/s12903017-0441-y.

5. Pierce DA, Preston DL. Radiation-related cancer risks at low doses among atomic bomb survivors. Radiat Res 2000;154(2):178-186. DOI: 10.1667/0033-7587(2000)154[0178:RRCRAL]2.0.CO;2.

6. Preston $\mathrm{DL}$, Ron $\mathrm{E}$, et al. Solid cancer incidence in atomic bomb survivors: 1958-1998. Radiat Res 2007;168(1):1-64. DOI: 10.1667/ RR0763.1.

7. Preston DL, Pierce DA, et al. Dose response and temporal patterns of radiation-associated solid cancer risks. Health Phys 2003;85(1):43-46. DOI: 10.1097/00004032-200307000-00010.

8. Kassebaum DK, Nummikoski PV, et al. Cross sectional radiography for implant site assessment. Oral Surg Oral Med Oral Pathol 1990;70: 674-678. DOI: 10.1016/0030-4220(90)90421-N. 
9. Jaju PP, Jaju SP. Clinical utility of dental cone-beam computed tomography: current perspectives. Clin Cosmet Investig Dent 2014;6:29-43. DOI: 10.2147/CCIDE.S41621.

10. D'Haese J, Ackhurst J, et al. Current state of the art of computerguided implant surgery. Periodontol 2000 2017;73:121-133. DOI: 10.1111/prd.12175.

11. Van Assche N, van Steenberghe D, et al. Accuracy of implant placement based on presurgical planning of three-dimensional cone beam images: a pilot study. J Clin Periodontal 2007;34:816-821. DOI: 10.1111/j.1600-051X.2007.01110.x.

12. Perez LA, Brooks SL, et al. Comparison of linear tomography and direct ridge mapping for the determination of edentulous ridge dimensions in human cadavers. Oral Surg Oral Med Oral Pathol Oral Radiol Endod 2005;99:748-754. DOI: 10.1016/j.tripleo.2004.10.023.

13. Chen LC, Lundgren T, et al. Comparison of different methods of assessing alveolar ridge dimensions prior to dental implant placement. J Priodontal 2008;79:401-405. DOI: 10.1902/jop.2008.070021.

14. Reyes A, Turkyilmaz I, et al. Accuracy of surgical guides made from conventional and a combination of digital scanning and rapid prototyping techniques. J Prosthet Dent 2015;113(4):295-303. DOI: 10.1016/j.prosdent.2014.09.018.
15. Burns DR, Crabtree DG, et al. Template for positioning and angulation of intraosseous implants. J Prosthet Dent 1988;60:479-483. DOI: 10.1016/0022-3913(88)90253-3.

16. Stumpel L. Cast based guided implant placement; a novel technique. J Prosthet Dent 2008;100:61-69. DOI: 10.1016/S0022-3913(08) 60140-7.

17. Park C, Raigrodski AJ, et al. Accuracy of implant placement using precision surgical guides with varying occlusogingival heights: An in vitro study. J Prosthet Dent 2009;101:372-381. DOI: 10.1016/S00223913(09)60080-9.

18. Pesun IJ, Gardner FM. Fabrication of a guide for radiographic evaluation and surgical placements of implants. J Prosthet Dent 1995;73:548-552. DOI: 10.1016/S0022-3913(05)80114-3.

19. Sicilia A, Enrile FJ, et al. Evaluation of the precision obtained with a fixed surgical template in the placement of implants for rehabilitation of the completely edentulous maxilla: a clinical report. Int J Oral Maxillofac Implants 2000;15:272-277.

20. Fajardo RJ, Ryan TM, et al. Assessing the accuracy of high-resolution $\mathrm{X}$-ray computed tomography of primate trabecular bone by comparisons with histological sections. Am J Phys Anthropol 2002 May;118(1):1-10. DOI: 10.1002/ajpa.10086. 